The Journal of Experimental Biology 214, 2522-2527 (C) 2011. Published by The Company of Biologists Ltd doi:10.1242/jeb.055764

RESEARCH ARTICLE

\title{
Myostatin levels in skeletal muscle of hibernating ground squirrels
}

\author{
Naomi E. Brooks ${ }^{1, *}$, Kathryn H. Myburgh ${ }^{1}$ and Kenneth B. Storey ${ }^{2}$ \\ ${ }^{1}$ Department of Physiological Sciences, Stellenbosch University, Matieland, 7602 Stellenbosch, South Africa and ${ }^{2}$ Institute of \\ Biochemistry and Department of Biology, Carleton University, 1125 Colonel By Drive, Ottawa, ON K1S 5B6, Canada \\ *Author for correspondence (nbrooks@sun.ac.za)
}

Accepted 19 April 2011

\begin{abstract}
SUMMARY
Myostatin, a negative regulator of muscle mass, is elevated during disuse and starvation. Mammalian hibernation presents a unique scenario, where animals are hypocaloric and in torpor, but the extent of muscle protein loss is minimized. We hypothesized that myostatin expression, which is usually increased early in disuse and under hypocaloric conditions, could be suppressed in this unique model. Skeletal muscle was collected from thirteen-lined ground squirrels, Spermophilus tridecemlineatus, at six time points during hibernation: control euthermic (CON); entrance into hibernation (ENT), body temperature $\left(T_{b}\right)$ falling; early hibernation (EHib), stable $T_{b}$ in torpor for $24 \mathrm{~h}$; late hibernation (LHib), stable $T_{b}$ in torpor for 3 days; early arousal (EAr), $T_{b}$ rising; and arousal (AR), $T_{b}$ restored to $34-37^{\circ} \mathrm{C}$ for about $18 \mathrm{~h}$. There was no significant increase of myostatin during ENT, EHib or LHib. Unexpectedly, there were approximately sixfold increases in myostatin protein levels as squirrels arose from torpor. The elevation during EAr remained high in AR, which represented an interbout time period. Mechanisms that could release the suppression or promote increased levels of myostatin were assessed. SMAD2 and phosphorylated SMAD2 were increased during EHib, but only the phosphorylated SMAD2 during AR mirrored increases in myostatin. Follistatin, a negative regulator of myostatin, did not follow the same time course as myostatin or its signaling pathway, indicating more control of myostatin at the signaling level. However, SMAD7, an inhibitory SMAD, did not appear to play a significant role during deep hibernation. Hibernation is an excellent natural model to study factors involved in the endogenous intracellular mechanisms controlling myostatin.
\end{abstract}

Key words: hibernation, myostatin, skeletal muscle.

\section{INTRODUCTION}

Myostatin (growth-differentiation factor 8, GDF8) is a member of the transforming growth factor beta (TGF $\beta$ ) superfamily and a negative regulator of muscle mass. Animals with a polymorphism in the myostatin gene that renders it less active have hypertrophied muscles. This is seen in 'double-muscled' cattle (Grobet et al., 1997; Kambadur et al., 1997; McPherron and Lee, 1997), a human child with significant hypertrophy (Schuelke et al., 2004) and myostatin knock-out mice (McPherron et al., 1997), all of which demonstrate extensively hypertrophied muscles in response to myostatin gene mutation. Even with a normal myostatin gene, if expression is blocked experimentally, muscles hypertrophy, growing in size by $13-30 \%$ (Whittemore et al., 2003). Conversely, overexpression of myostatin leads to muscle atrophy (Reisz-Porszasz et al., 2003). Members of the TGF $\beta$ superfamily bind to membrane receptors and trigger the phosphorylation and activation of the SMADs (Mothers against decapentaplegic), a family of signal transducers (Zhu et al., 2004). TGF $\beta$ family members play a role in many cellular functions and communications. Different members of the TGF $\beta$ superfamily signal through various receptors and pathways (for a review, see Ross and Hill, 2008). Induction of the pathway by either TGF $\beta$ or nodal or Activin ligands leads to phosphorylation of SMAD2 and SMAD3 (Tsuchida, 2004; Zhu et al., 2004), whereas bone morphogenetic protein (BMP) and growth and differentiation factor (GDF) ligands induce phosphorylation of SMAD1, SMAD5 and SMAD8 (Massague and Gomis, 2006). Activated SMADs form a complex with SMAD4 and are transported to the nucleus to regulate target gene expression.
The myostatin promoter region contains a binding site for this complex; thus, SMAD2 is both downstream of the receptor-myostatin complex and upstream of myostatin expression (Allen and Unterman, 2007). The induction of myostatin expression by regulatory SMADs was traced unequivocally to SMAD2 protein.

Situations of muscle disuse in mammals typically lead to increased myostatin mRNA (Reardon et al., 2001) and protein (Shao et al., 2007). However, how does this response differ in mammalian hibernators - the champions of muscle mass retention during extended periods of disuse? During the hibernating season, small mammals undergo long periods of deep cold torpor (1-2 weeks) with core body temperature $\left(T_{\mathrm{b}}\right)$ often close to $0^{\circ} \mathrm{C}$ (Storey and Storey, 2007 ) and with little or no skeletal muscle activity (Wickler et al., 1991). Torpor episodes are interspersed with short periods $(<24 \mathrm{~h})$ of arousal when animals rewarm to euthermia. Despite long periods of inactivity, large hibernators such as bears appear to avoid protein loss and maintain muscle functional capacity (Harlow et al., 2001; Lohuis et al., 2007). This phenomenon is not peculiar to bears, as resistance to atrophy is also found in golden-mantled ground squirrels (Rourke et al., 2004a; Rourke et al., 2004b), dormice (Malatesta et al., 2009) and lower vertebrates such as turtles (McDonagh et al., 2004).

Myonuclei of hibernating dormice are not different from euthermic controls and apoptosis is not a feature (Malatesta et al., 2009). Therefore, the control of protein synthesis and degradation in hibernator muscles is likely pre-transcriptional at the level of cell signaling, via either activation of growth promoting pathways or 
suppression of catabolic processes. Various signaling candidates have been investigated, for example the AKT/protein kinase $\mathrm{B}$ (PKB) signaling pathway (Abnous et al., 2008) and various mitogenactivated protein kinases (MAPKs) (Eddy and Storey, 2007; MacDonald and Storey, 2005). We hypothesized that control of skeletal muscle mass during hibernation of thirteen-lined ground squirrels, Spermophilus tridecemlineatus may be linked to changes in the natural muscle negative regulator, myostatin, and its key downstream signaling molecules, particularly SMAD2. SMAD2 has been linked both directly and temporally with myostatin expression (Shao et al., 2007).

SMAD7 is an inhibitor SMAD and competes with regulatory SMADs such as SMAD2, resulting in inhibition of TGF $\beta$ and activin signaling (Nakao et al., 1997). SMAD7 negatively regulates myostatin signaling (Zhu et al., 2004) and may function as a negative feedback inhibitor for the pathway (Zhu et al., 2004). Myostatin function can also be inhibited by binding to the binding protein follistatin. Follistatin inhibits myostatin activity and, by doing so, promotes muscle growth (Lee, S. J. et al., 2010). Follistatin binds directly to myostatin and prevents myostatin binding to its receptor (Lee and McPherron, 2001). This inhibition is therefore not dependent on the signaling network. However, even in the absence of myostatin (myostatin-null mice), overexpression of follistatin causes a substantial increase in muscle mass revealing that it may also have an independent effect. These data reveal the complexity of muscle growth and maintenance through the TGF $\beta$ related signaling (Lee, 2007). We therefore further hypothesized that follistatin and SMAD7 would play a role in the complex inhibition of myostatin alone or the myostatin-SMAD2 pathway.

\section{MATERIALS AND METHODS} Animal collection and hibernation protocol

Thirteen-lined ground squirrels, S. tridecemlineatus (Mitchell 1821), were captured by a trapper licensed by the United States Department of Agriculture (TLS Research, Bartlett, IL, USA) using humane traps. Male squirrels were used for hibernation studies as previously described; temperature transponders implanted under the skin allowed body temperature $\left(T_{\mathrm{b}}\right)$ to be monitored to identify sampling times (Bratincsák et al., 2007). Studies took place within the natural hibernation season (January and February) in the Northern Hemisphere. Squirrels typically entered their first bout of deep torpor within 3 to 8 days of transfer to the hibernation cold chamber. For sampling, animals were anesthetized with isoflurane and decapitated within 2 min of removal from the hibernation chamber. Tissues were rapidly excised, flash frozen in liquid nitrogen, transported to their destination on dry ice and then stored at $-80^{\circ} \mathrm{C}$ until use. All animal procedures were approved by the Animal Care and Use Committee of the National Institute of Neurological Disorders and Stroke (National Institutes of Health, Bethesda, MD, USA; animal protocol no. ASP 1223-05). Skeletal muscle (all hindlimb thigh muscles from each animal homogenized) of thirteen-lined ground squirrels was sampled at multiple time points over hibernation bouts, as defined in Bratincsák et al. (Bratincsák et al., 2007): control euthermic $(\mathrm{CON})$; entrance into hibernation (ENT), with $T_{\mathrm{b}}$ decreasing ranging from 31 to $18^{\circ} \mathrm{C}$ (at least two successive temperature readings showed a decreasing $T_{\mathrm{b}}$ ); early hibernation (EHib), animals showed a stable $T_{\mathrm{b}}$ of $5-8^{\circ} \mathrm{C}$ for $24 \mathrm{~h}$; late hibernation (LHib), animals in torpor for at least 3 days with a stable $T_{\mathrm{b}}$ of $5-8^{\circ} \mathrm{C}$; early arousal (EAr), with $T_{\mathrm{b}}$ rising and increased respiration rate $\geq 60 \mathrm{~min}^{-1}$; and arousal (AR), with a $T_{\mathrm{b}}$ of at least $34-37^{\circ} \mathrm{C}$ for about $18 \mathrm{~h}$. Note that CON combined data from two types of control animals, those housed at room temperature and those that were in the cold room $\left(4-5^{\circ} \mathrm{C}\right)$, which were capable of entering torpor but had not reentered hibernation; initial trials found no significant differences between these groups for any parameter measured.

\section{Tissue preparation}

Frozen tissue samples were ground to a powder under liquid nitrogen and then quickly weighed and homogenized in buffer (1:3 w:v) $\left(20 \mathrm{mmoll}^{-1}\right.$ HEPES, $200 \mathrm{mmoll}^{-1} \mathrm{NaCl}, 0.1 \mathrm{mmoll}^{-1}$ EDTA, $10 \mathrm{mmoll}^{-1} \mathrm{NaF}, 1 \mathrm{mmoll}^{-1} \mathrm{Na}_{3} \mathrm{VO}_{4}, 10 \mathrm{mmoll}^{-1} \beta$-glycerophosphate dissolved in $\mathrm{ddH}_{2} \mathrm{O}$ ) together with $1 \mathrm{mmoll}^{-1}$ phenylmethylsulfonyl fluoride and $1 \mu$ protease inhibitor (SigmaAldrich, St Louis, MO, USA) using a Polytron PT1000 homogenizer. For SMAD7 and follistatin analysis, samples were homogenized and lysed [200 $\mathrm{mmoll}^{-1} \mathrm{HEPES}, 5 \mathrm{moll}^{-1} \mathrm{NaCl}, 10 \%$ Triton X-100, 0.5 moll $^{-1}$ EDTA, 1 moll $^{-1}$ dithiothreitol (DTT), $0.25 \mathrm{~g}$ Na-deoxycolate, $0.05 \mathrm{~g}$ sodium dodecyl sulfate (SDS)]. After centrifugation for $10 \mathrm{~min}$ at $10,000 \mathrm{~g}$, soluble protein content of the resulting supernatant was determined using the Bradford method (Bradford, 1976) and the commercial reagent from Bio-Rad (Hercules, CA, USA). All samples were adjusted to a set protein concentration by adding small amounts of the above buffer and then aliquots $(250 \mu \mathrm{l})$ were mixed 1:1 v:v with SDS-PAGE loading buffer (100 $\mathrm{mmoll}^{-1}$ Tris-HCl, pH6.8, 4\% w:v SDS, 20\% v:v glycerol, $0.2 \% \mathrm{w}: \mathrm{v}$ Bromophenol Blue, 10\% v:v 2-mercaptoethanol). The mixture was boiled for $5 \mathrm{~min}$, cooled on ice and frozen at $-20^{\circ} \mathrm{C}$.

\section{Western blotting}

Samples $(50 \mu \mathrm{g}$ soluble protein) were loaded into each well of $10 \%$ SDS-PAGE gels and separated at $180 \mathrm{~V}$ for $45 \mathrm{~min}$ followed by transfer to polyvinylidene difluoride membranes. Membranes were blocked for $30 \mathrm{~min}$ in Tris-buffered saline containing Tween 20 (TBST) $\left(20 \mathrm{mmoll}^{-1}\right.$ Tris base, $140 \mathrm{mmoll}^{-1} \mathrm{NaCl}, 0.1 \%$ Tween 20 ) with $2.5 \%$ non-fat dried milk added and then incubated at $4^{\circ} \mathrm{C}$ overnight with primary antibodies diluted in TBST. Antibodies were rabbit polyclonal anti-myostatin (1:2000; Millipore, Billerica, MA, USA), rabbit polyclonal antibodies against SMAD2, phosphorylated SMAD2, SMAD5 and phosphorylated SMAD1/5 (diluted 1:1000; Cell Signaling Technology, Danvers, MA, USA). After incubation, blots were washed three times with TBST and incubated at room temperature for $30 \mathrm{~min}$ with secondary anti-rabbit (Cell Signaling Technology) IgG conjugated to horseradish peroxidase (1:4000 dilution in TBST). Signal detection used enhanced chemiluminescence (ECL), bands were visualized using a ChemiGenius imaging system (Syngene, Frederick, MD, USA) and band intensities were analyzed using the associated Gene Tools software. Membranes were then stained with Coomassie Blue and rescanned to confirm equal loading of proteins in each lane; a section of sharp bands that were present in all samples were scanned and the densities summed. Intensity of the immunoreactive band in each lane was normalized to the summed intensity of these Coomassiestained bands in the same lane to correct for any slight differences in loading. The polyclonal myostatin antibody detected a single protein band (at $\sim 25 \mathrm{kDa}$ ) corresponding to active myostatin. Additionally, a very faint band $>55 \mathrm{kDa}$ was seen, possibly representing promyostatin. This was not quantified.

For SMAD7 and follistatin proteins, the above protocol was followed with the following amendments: membranes were incubated overnight with rabbit anti-follistatin (1:1000, Abcam, 47941, Cambridge, MA, USA) or rabbit anti-SMAD7 (1:1000, Invitrogen), or $\beta$-actin (Cell Signaling Technology), incubated with anti-rabbit secondary antibody for $1 \mathrm{~h}$ at room temperature $(1: 1000$, GE Healthcare, Piscataway, NJ, USA). Detection was done using 
ECL $^{\mathrm{TM}}$ Western Blotting Detection Reagent (GE Healthcare) and band analysis was performed with the ImageJ 1.41 software (http://rsb.info.nih.gov/ij). Each band was normalized to the $\beta$-actin serving as control for small differences in loading.

\section{Statistical analysis}

Data are presented as means \pm s.e.m.; $N=4$ at all time points for all parameters, except CON ( $N=8)$. For follistatin and SMAD7, $N=4$ for CON. Mean normalized band densities were compared using one-way ANOVA and Fisher's least significant difference (LSD) post hoc test using SPSS 18.0 (IBM, Armonk, NY, USA). The level of significance was set at $P \leq 0.05$.

\section{RESULTS}

The results are an indication of changes in mixed skeletal muscle samples. The present study analyzed myostatin and total and phosphorylated levels of SMAD2 at six time points over the course of a hibernation cycle. Further, the present study measured follistatin and SMAD7, two possible regulators of myostatin over four time points of hibernation, and total SMAD5 and phosphorylated levels of SMAD1 or SMAD5 as a possible alternative to the SMAD2 pathway active throughout hibernation.

\section{Myostatin}

Myostatin protein levels during the initial phases, ENT, EHib and LHib, did not change significantly compared with control values (Fig. 1). However, myostatin protein levels were 4.7-fold above control values in EAr $(P \leq 0.01)$ and 3.8-fold above control values in $\operatorname{AR}(P \leq 0.05)$ groups.

\section{SMAD2 and phosphorylated SMAD2}

Total SMAD2 protein increased significantly during EHib by approximately threefold $(P \leq 0.001$ compared with control and $P \leq 0.001$ compared with all other groups), but returned to basal levels after this time point (Fig. 2A). Phosphorylated SMAD2 (Fig.2B) also increased during EHib to approximately fourfold greater levels than

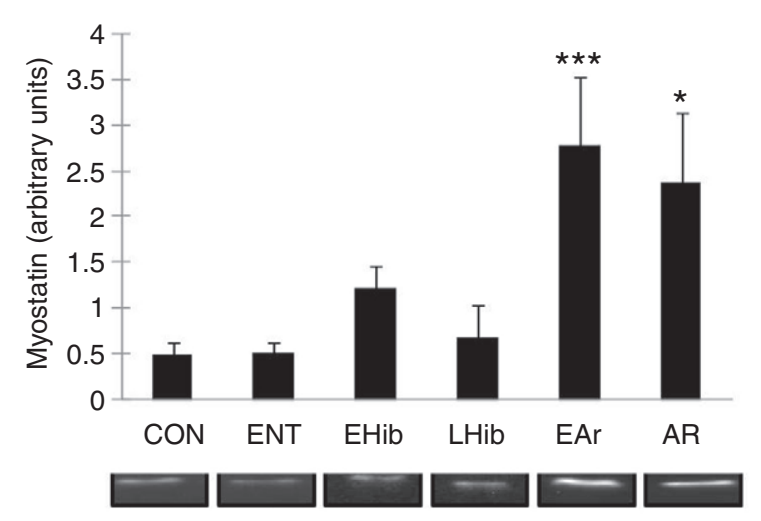

Fig. 1. Myostatin protein levels are maintained at pre-hibernation levels during hibernation but rise significantly during arousal from torpor in thirteen-lined ground squirrels. Data are means \pm s.e.m.; $N=4$, except CON $N=8$. Representative band densities, mainly obtained from different blots with equal protein loading, are presented separately. All bands were normalized to adjust for slight differences in loading and these values were used for statistical analysis. ANOVA indicated significant differences between groups $(P \leq 0.001)$. LSD post hoc tests: ${ }^{*} P \leq 0.05$ compared with control; ${ }^{* *} P \leq 0.001$ compared with control. CON, control euthermic; ENT, entrance into hibernation; EHib, early hibernation; LHib, late hibernation; EAr, early arousal; AR, fully aroused. control values $(P \leq 0.001)$. However, in EAr, protein levels of phosphorylated SMAD2 rose by approximately fivefold $(P \leq 0.001)$ and remained elevated during AR $(P \leq 0.001)$. Therefore, the extent of total and phosphorylated SMAD2 had congruent changes during EHib, but only the extent of phosphorylation was affected during AR.

\section{SMAD7}

SMAD7 is an inhibitory SMAD that causes inhibition of the SMAD signaling pathway (Nakao et al., 1997). ANOVA results suggested a trend towards a significant group effect $(P=0.089)$. No significant changes in SMAD7 were seen throughout torpor (EHib and LHib) but post hoc analysis did show that SMAD7 protein levels increased significantly during AR compared with LHib and EAr $(P \leq 0.05$; Fig. 3).

\section{Follistatin}

Follistatin is an antagonist of myostatin and functions to inhibit myostatin (Lee and McPherron, 2001). Follistatin levels increased by $\sim 1.5$-fold during EHib but values returned to baseline levels during LHib and EAr (Fig. 4). There was a significant reduction in follistatin during $\mathrm{AR}(P \leq 0.05$ compared with EHib).

SMAD5 and phosphorylated SMAD1/5

Total SMAD5 protein increased significantly during late hibernation by $\sim 1.5$-fold $(P \leq 0.001$ compared with control and $P \leq 0.001$
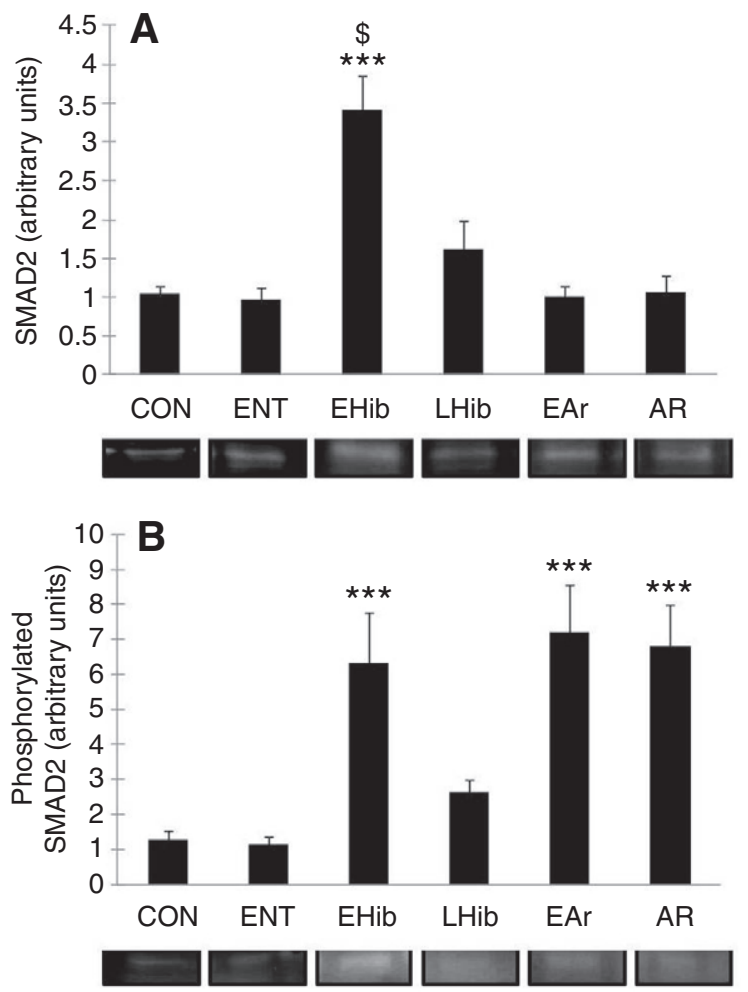

Fig. 2. (A) Total SMAD2 protein levels are significantly increased during EHib but subsequently return to basal levels. (B) The amount of phosphorylated SMAD2 is significantly increased during EHib, EAr and AR. Skeletal muscle of thirteen-lined ground squirrels was sampled at multiple time points over hibernation bouts (for abbreviations see Fig. 1 legend). Data are means \pm s.e.m.; $N=4$, except $C O N N=8$. For description of band density analysis and representation in this figure, see Fig. 1 legend. ANOVA indicated significant differences between groups $(P \leq 0.001)$. LSD post hoc tests: ${ }^{* * *} P \leq 0.001$ compared with control; ${ }^{\$} P \leq 0.001$ compared with all other groups. 


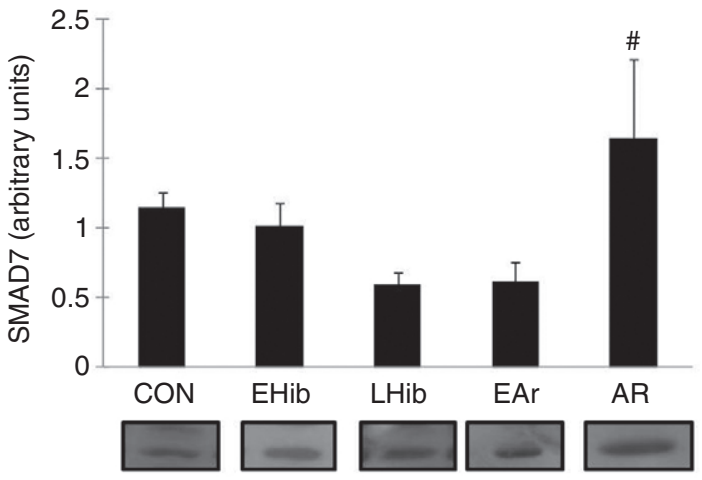

Fig. 3. SMAD7 protein levels are maintained during hibernation and increased during arousal from torpor. Skeletal muscle of thirteen-lined ground squirrels was sampled at multiple time points over hibernation bouts (for abbreviations see Fig. 1 legend). Data are means \pm s.e.m.; $N=4$. For description of band density analysis and representation in this figure, see Fig. 1 legend. ANOVA indicated a trend of difference between groups $(P=0.089)$. LSD post hoc tests: ${ }^{\#} P \leq 0.05$ compared with LHib and EAr.

compared with all other groups) but returned to baseline values after this time point (Fig. 5A). In contrast, similar to other signaling markers, phosphorylated SMAD1/5 (Fig. 5B) increased dramatically during EHib to approximately eightfold greater levels than the control ( $P \leq 0.001$ compared with control and $P \leq 0.001$ compared with all other groups) but returned slowly to baseline values during LHib and $\operatorname{EAr}(P \leq 0.05$ compared with control).

\section{DISCUSSION}

The present study investigated the signaling of myostatin through the SMAD2 pathway at six time points over the course of a hibernation bout in thirteen-lined ground squirrels. Because this signaling could be negatively regulated by SMAD7 or follistatin, the levels of these proteins were also investigated. Unexpectedly, myostatin protein levels did not change significantly during the initial phases of hibernation ENT and EHib, nor did they change during LHib compared with control values. By contrast, Shao et al. found immediate increases of myostatin mRNA and protein (within 1 day and sustained for 56 days) following denervation (Shao et al., 2007), which emphasizes the very different intracellular environment in the skeletal muscle of hibernating rodents compared with models of skeletal muscle disuse. This highlights that a lack of myostatin expression during hibernation is unique compared with other models.

During hibernation, metabolic rate is often reduced by $95 \%$ or more when core body temperatures fall to $0-5^{\circ} \mathrm{C}$ in mid-winter. Although there is a thermodynamic component, metabolic rate depression is largely a regulated process and particularly targets many energy-expensive cellular processes including a strong global suppression of the rates of transcription and translation (Morin and Storey, 2006; Storey and Storey, 2007). Although it would appear that $90 \%$ or more of all genes are suppressed during hibernation, myostatin protein is neither suppressed nor elevated during early hibernation and torpor. This finding in mixed muscle reflects that found in transcript levels of myostatin in gastrocnemius and plantaris muscles of squirrels (Nowell et al., 2011). However, it is also important to highlight that a significant decrease in myostatin mRNA was seen in the diaphragm and soleus muscle (Nowell et al., 2011).

Several key signaling pathways are elevated during hibernation: in Richardson's ground squirrels elevated levels of MAPKs

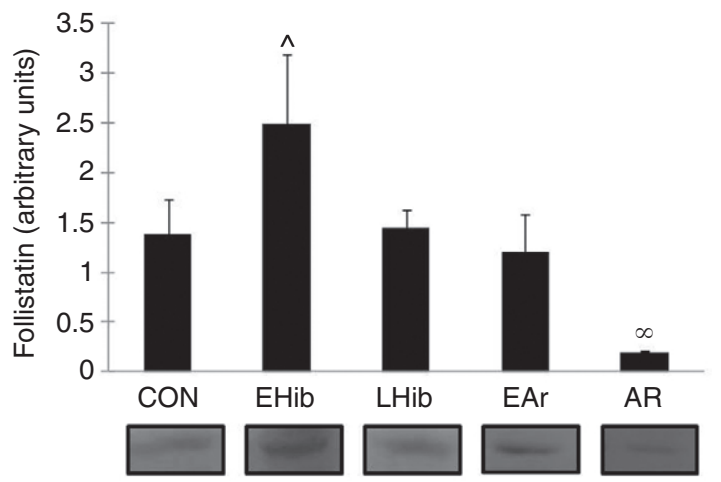

Fig. 4. Follistatin protein levels are reduced during arousal from torpor. Skeletal muscle of thirteen-lined ground squirrels was sampled at multiple time points over hibernation bouts (for abbreviations see Fig. 1 legend) Data are means \pm s.e.m.; $N=4$. For description of band density analysis and representation in this figure, see Fig. 1 legend. ANOVA indicated significant differences between groups $(P \leq 0.05)$. LSD post hoc tests: $\wedge P \leq 0.05$ compared with EAr and Ar; $\infty P \leq 0.05$ compared with EHib.

occurred in skeletal muscle during hibernation, including ERK2, JNK and phosphorylated p38 MAPK (MacDonald and Storey, 2005). The transcription factor targets (CREB, ATF-2 and Elk-1) of p38 MAPK also rose, indicating that signaling events are followed by translation of key factors (Eddy and Storey, 2007). A common marker of atrophy, the signaling protein MAFbx, is elevated during hibernation in both the gastrocnemius and plantaris muscle (Rourke et al., 2004b), but the elevation was not associated with atrophy itself, which was puzzling. The current data are the first to provide a potential explanation for catabolic control in hibernating ground squirrels as there was an absence of myostatin increase during early hibernation and torpor.

In deep torpor, the state most commonly analyzed in hibernation studies, both SMAD2 and phosphorylated SMAD2 did not differ from basal levels. However, because more time points were analyzed in the present study, we were able to determine that total SMAD2 protein and phosphorylated SMAD2 increased significantly during EHib. Elevations in total SMAD2 would serve to amplify the consequences of signals promoting increased SMAD2 phosphorylation, suggesting that this part of the TGF $\beta$ superfamily signaling cascade may be important in establishing the cold torpid state.

The second striking result of the present study is the strong elevation of myostatin protein during EAr and the maintenance of high myostatin in fully aroused animals sampled $\sim 18 \mathrm{~h}$ after reestablishing the euthermic body temperature of $\sim 37^{\circ} \mathrm{C}$. A number of recent publications have highlighted the importance of shivering during the arousal phase where the hibernating animals return to normal body temperature for a short period of time. Lee et al. postulated that the maintenance of muscle mass during hibernation could be related to the interspersed arousal phases (Lee et al., 2010). Indeed, the periodic bouts of arousal were associated with increases in muscle contraction and motor unit activities in hibernating bats (Lee et al., 2010). However, we have shown that both early arousal and arousal are accompanied by an increase in myostatin, which would argue against muscle anabolism stimulated by shivering. Rather, the low myostatin during early and late hibernation would argue that the resistance to atrophy is regulated during torpor rather than during periodic arousal. A possible explanation is an interaction between the humoral stress response and myostatin. Cortisol is a 

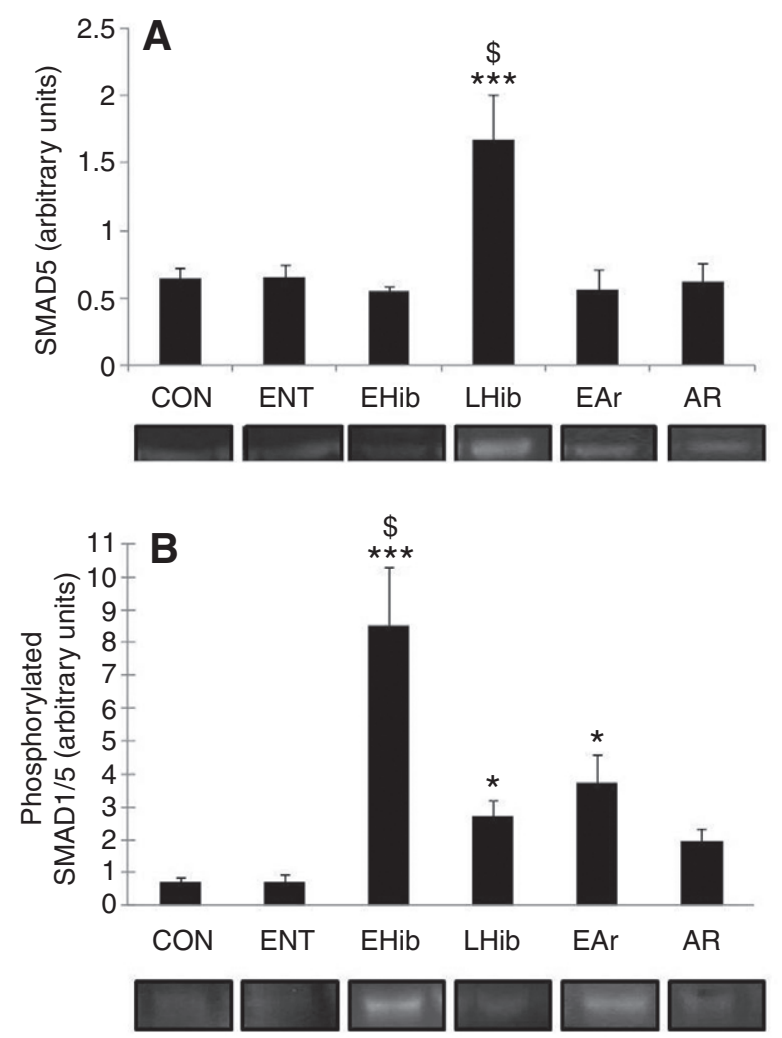

Fig. 5. (A) Total SMAD5 protein levels are significantly increased during LHib but subsequently return to basal levels. (B) The amount of phosphorylated SMAD1/5 is significantly increased during EHib. Skeletal muscle of thirteen-lined ground squirrels was sampled at multiple time points over hibernation bouts (for abbreviations see Fig. 1 legend). Data are means \pm s.e.m.; $N=4$, except $C O N N=8$. For description of band density analysis and representation in this figure, see legend to Fig. 1. ANOVA indicated significant differences between groups $(P \leq 0.001)$. LSD post hoc tests: ${ }^{*} P \leq 0.05$ compared with control; ${ }^{* * *} P \leq 0.001$ compared with control; $\$ P \leq 0.001$ compared with all other groups.

known stimulus for muscle atrophy and here it is important to note that the atrophic effect of dexamethasone treatment in mice can be completely abolished by myostatin knock-out (Gilson et al., 2007).

It is intriguing that myostatin translation is activated in EAr, much sooner than the resumption of normal body temperature. There is a clear congruence during EAr and AR phases of the hibernation cycle between phosphorylated SMAD2 and myostatin protein levels; both increased dramatically (fivefold to sixfold) when animals arose from torpor. This suggests a myostatin-initiated increase in SMAD2 phosphorylation because it is known that myostatin acts through the SMAD2 pathway. Although SMAD2 is a signaling protein downstream of myostatin, overexpression of SMAD2 also increases myostatin expression (Allen and Unterman, 2007), suggesting that a positive feedback loop (myostatin-SMAD2-myostatin) operates under certain conditions, including hibernation. However, we did not observe this positive feedback loop during early hibernation or deep torpor: the increase in SMAD2 protein and phosphorylation levels in EHib were not accompanied by any substantial increase in myostatin. Therefore, other mechanisms must exist to prevent its downstream effect on myostatin transcription and/or translation during entry into and during torpor.
Inhibition of the SMAD-complex translocation to the nucleus is a possible explanation. There is a precedent in the literature for decreased SMAD2 translocation under pathological conditions such as Alzheimer's disease, where phosphorylated SMAD2 is elevated in neuronal cytoplasm, but without concomitant nuclear localization (Lee et al., 2006). Hibernation may also cause uncoupling of this pathway.

It is known that follistatin may prevent myostatin from binding to its receptor (Lee and McPherron, 2001). We found that increased myostatin in AR occurred alongside a significant reduction in follistatin. Therefore, instead of the follistatin protein-protein interaction with myostatin preventing the actions of myostatin (Amthor et al., 2004), the reduction in follistatin found here would serve to further enhance the response to elevated myostatin during AR. The reduction in follistatin followed after the increase in myostatin, possibly indicating separate mechanisms of control. However, increased phosphorylated SMAD2 mirrored increased myostatin, and did not change when follistatin was reduced in AR. The reduction in follistatin may therefore have an effect on alternative pathways such as the AKT pathway (Trendelenburg et al., 2009). It has also been reported that follistatin increases satellite cell proliferation, possibly by blocking myostatin (Gilson et al., 2009). A recent study reported no change in muscle fibre shape and size or fibre type during hibernation (Malatesta et al., 2009). Furthermore, they also reported that nuclear and mitochondrial activity is maintained during deep torpor (measurement of one time point during hibernation). Further investigation is warranted to investigate mitochondria, myonuclei and satellite cell nuclei during AR.

SMAD7 is an inhibitory SMAD. Transcription of SMAD7 is initiated by both TGF $\beta$ and activation provides a regulatory feedback mechanism to terminate signaling through the activated receptors (Nakao et al., 1997). We report increased levels of SMAD7 during AR from hibernation. The increased SMAD7 levels may be indicative of an inhibitory control in response to the increased myostatin levels at this time point. Although this response is delayed compared with the myostatin increase in EAr, it could compensate for the reduced follistatin levels at the same time point. Importantly, SMAD7 does not appear to play any inhibitory role during EHib or LHib.

We also report changes in SMAD5 and phosphorylated SMAD1/5 levels during hibernation. There are a number of signaling pathways influenced by different members of the TGF $\beta$ superfamily. In comparison to myostatin's signaling through the SMAD2 cascade, BMP ligands act by inducing phosphorylation of SMAD1, SMAD5 and SMAD8 (Massague and Gomis, 2006). Levels of phosphorylated SMAD1/5 follow a similar time course to SMAD2 with elevated levels at EHib. This may be further indicative of important changes that the muscle undergoes in adaption to the cold torpid state and suggests that these changes result in a response in members of the TGF $\beta$ superfamily. SMAD5 protein levels were increased in deep torpor, in contrast to all of the other measures in this study, including SMAD2. Previous studies have shown inconsistencies with total protein and phosphorylated protein levels; for example, Abnous et al. found no change in AKT protein levels whereas activated phosphorylated AKT was reduced by approximately $40 \%$ in skeletal muscle of hibernating Richardson's ground squirrels compared with euthermic controls (Abnous et al., 2008). The animal may display a disparate response as hibernation progresses, particularly during deep torpor. The results of this study also demonstrate the complex interplay of the various SMAD pathways and the response to hibernation. 


\section{Conclusions}

In conclusion, mammals generally lack the ability to prevent significant atrophy. Increases in myostatin have been associated with conditions that promote muscle protein loss. Here we present data that clearly indicate that myostatin expression in our model is different from the currently accepted dogma for other mammals. Therefore, ground squirrels and other hibernating species can provide a natural model to study mechanisms for myostatin regulation.

Clearly, the evidence is mounting that: (1) during torpor, skeletal muscle retains significant intracellular activity, even at very low $T_{\mathrm{b}}$ values; (2) this activity exhibits variations when multiple time points are assessed throughout the various stages of hibernation and arousal; (3) the TGF $\beta$ superfamily signaling molecule SMAD2, although known to be related to myostatin, does not follow the same temporal pattern except during the arousal phases of the cycle; (4) myostatin is inhibited during torpor, but rises when animals undergo arousal, remaining high; and (5) follistatin does not follow the same time course as myostatin or its signaling components, indicating that control of myostatin does not occur by inhibiting its receptor binding but is more likely to occur at the signaling level. In addition, SMAD7 does not appear to play a significant inhibitory role during deep hibernation.

\section{ACKNOWLEDGEMENTS}

We thank Dr J. M. Hallenbeck, National Institute of Neurological Disorders and Stroke, N.I.H., Bethesda, MD, USA, for providing ground squirrel tissues. N.E.B. held a postdoctoral fellowship from Stellenbosch University and a travel grant from the Journal of Experimental Biology. Research was supported by the South African National Research Foundation and Medical Research Council (Myburgh laboratory) and the Natural Sciences and Engineering Research Council of Canada and Canada Research Chairs program (Storey laboratory).

\section{REFERENCES}

Abnous, K., Dieni, C. A. and Storey, K. B. (2008). Regulation of Akt during hibernation in Richardson's ground squirrels. Biochim. Biophys. Acta 1780, 185-193.

Allen, D. L. and Unterman, T. G. (2007). Regulation of myostatin expression and myoblast differentiation by FoxO and SMAD transcription factors. Am. J. Physiol. 292, C188-C199.

Amthor, H., Nicholas, G., McKinnell, I., Kemp, C. F., Sharma, M., Kambadur, R. and Patel, K. (2004). Follistatin complexes Myostatin and antagonises Myostatinmediated inhibition of myogenesis. Dev. Biol. 270, 19-30.

Bradford, M. M. (1976). A rapid and sensitive method for the quantitation of microgram quantities of protein utilizing the principle of protein-dye binding. Anal. Biochem. 72, 248-254.

Bratincsák, A., McMullen, D., Miyake, S., Toth, Z. E., Hallenbeck, J. M. and Palkovits, M. (2007). Spatial and temporal activation of brain regions in hibernation: $c$-fos expression during the hibernation bout in thirteen-lined ground squirrel. J. Comp. Neurol. 505, 443-458.

Eddy, S. F. and Storey, K. B. (2007). p38 MAPK regulation of transcription factor targets in muscle and heart of the hibernating bat, Myotis lucifugus. Cell Biochem. Funct. 25, 759-765.

Gilson, H., Schakman, O., Combaret, L., Lause, P., Grobet, L., Attaix, D., Ketelslegers, J. M. and Thissen, J. P. (2007). Myostatin gene deletion prevents glucocorticoid-induced muscle atrophy. Endocrinology 148, 452-460.

Gilson, H., Schakman, O., Kalista, S., Lause, P., Tsuchida, K. and Thissen, J. P. (2009). Follistatin induces muscle hypertrophy through satellite cell proliferation and inhibition of both myostatin and activin. Am. J. Physiol. Endocrinol. Metab. 297, E157-E164.

Grobet, L., Martin, L. J., Poncelet, D., Pirottin, D., Brouwers, B., Riquet, J., Schoeberlein, A., Dunner, S., Menissier, F., Massabanda, J. et al. (1997). A deletion in the bovine myostatin gene causes the double-muscled phenotype in cattle. Nat. Genet. 17, 71-74.

Harlow, H. J., Lohuis, T., Beck, T. D. and laizzo, P. A. (2001). Muscle strength in overwintering bears. Nature 409, 997.

Kambadur, R., Sharma, M., Smith, T. P. and Bass, J. J. (1997). Mutations in myostatin (GDF8) in double-muscled Belgian Blue and Piedmontese cattle. Genome Res. 7, 910-916.
Lee, H. G., Ueda, M., Zhu, X., Perry, G. and Smith, M. A. (2006). Ectopic expression of phospho-Smad2 in Alzheimer's disease: uncoupling of the transforming growth factor-beta pathway? J. Neurosci. Res. 84, 1856-1861.

Lee, K., So, H., Gwag, T., Ju, H., Lee, J. W., Yamashita, M. and Choi, I. (2010). Molecular mechanism underlying muscle mass retention in hibernating bats: role of periodic arousal. J. Cell. Physiol. 222, 313-319.

Lee, S. J. (2007). Quadrupling muscle mass in mice by targeting TGF-beta signaling pathways. PLOS ONE 2, e789.

Lee, S. J. and McPherron, A. C. (2001). Regulation of myostatin activity and muscle growth. Proc. Natl. Acad. Sci. USA 98, 9306-9311.

Lee, S. J., Lee, Y. S., Zimmers, T. A., Soleimani, A., Matzuk, M. M., Tsuchida, K., Cohn, R. D. and Barton, E. R. (2010). Regulation of muscle mass by follistatin and activins. Mol. Endocrinol. 24, 1998-2008.

Lohuis, T. D., Harlow, H. J., Beck, T. D. and laizzo, P. A. (2007). Hibernating bears conserve muscle strength and maintain fatigue resistance. Physiol. Biochem. Zool. 80, 257-269.

MacDonald, J. A. and Storey, K. B. (2005). Mitogen-activated protein kinases and selected downstream targets display organ-specific responses in the hibernating ground squirrel. Int. J. Biochem. Cell Biol. 37, 679-691.

Malatesta, M., Perdoni, F., Battistelli, S., Muller, S. and Zancanaro, C. (2009). The cell nuclei of skeletal muscle cells are transcriptionally active in hibernating edible dormice. BMC Cell Biol. 10, 19.

Massague, J. and Gomis, R. R. (2006). The logic of TGFbeta signaling. FEBS Lett. 580, 2811-2820.

McDonagh, J. C., Callister, R. J., Favron, M. L. and Stuart, D. G. (2004). Resistance to disuse atrophy in a turtle hindlimb muscle. J. Comp. Physiol. A 190 321-329.

McPherron, A. C. and Lee, S. J. (1997). Double muscling in cattle due to mutations in the myostatin gene. Proc. Natl. Acad. Sci. USA 94, 12457-12461.

McPherron, A. C., Lawler, A. M. and Lee, S. J. (1997). Regulation of skeletal muscle mass in mice by a new TGF-beta superfamily member. Nature $\mathbf{3 8 7}, 83-90$.

Morin, P., Jr and Storey, K. B. (2006). Evidence for a reduced transcriptional state during hibernation in ground squirrels. Cryobiology 53, 310-318.

Nakao, A., Afrakhte, M., Moren, A., Nakayama, T., Christian, J. L., Heuchel, R., Itoh, S., Kawabata, M., Heldin, N. E., Heldin, C. H. et al. (1997). Identification of Smad7, a TGFbeta-inducible antagonist of TGF-beta signalling. Nature 389, 631635.

Nowell, M. M., Choi, H. and Rourke, B. C. (2011). Muscle plasticity in hibernating ground squirrels (Spermophilus lateralis) is induced by seasonal, but not lowtemperature, mechanisms. J. Comp. Physiol. B 181, 147-164.

Reardon, K. A., Davis, J., Kapsa, R. M., Choong, P. and Byrne, E. (2001) Myostatin, insulin-like growth factor-1, and leukemia inhibitory factor mRNAs are upregulated in chronic human disuse muscle atrophy. Muscle Nerve 24, 893-899.

Reisz-Porszasz, S., Bhasin, S., Artaza, J. N., Shen, R., Sinha-Hikim, I., Hogue, A., Fielder, T. J. and Gonzalez-Cadavid, N. F. (2003). Lower skeletal muscle mass in male transgenic mice with muscle-specific overexpression of myostatin. Am. J. Physiol. 285, E876-E888.

Ross, S. and Hill, C. S. (2008). How the Smads regulate transcription. Int. J. Biochem. Cell Biol. 40, 383-408.

Rourke, B. C., Qin, A., Haddad, F., Baldwin, K. M. and Caiozzo, V. J. (2004a). Cloning and sequencing of myosin heavy chain isoform cDNAs in golden-mantled ground squirrels: effects of hibernation on mRNA expression. J. Appl. Physiol. 97, 1985-1991.

Rourke, B. C., Yokoyama, Y., Milsom, W. K. and Caiozzo, V. J. (2004b). Myosin isoform expression and MAFbx mRNA levels in hibernating golden-mantled ground squirrels (Spermophilus lateralis). Physiol. Biochem. Zool. 77, 582-593.

Schuelke, M., Wagner, K. R., Stolz, L. E., Hubner, C., Riebel, T., Komen, W., Braun, T., Tobin, J. F. and Lee, S. J. (2004). Myostatin mutation associated with gross muscle hypertrophy in a child. N. Engl. J. Med. 350, 2682-2688.

Shao, C., Liu, M., Wu, X. and Ding, F. (2007). Time-dependent expression of myostatin RNA transcript and protein in gastrocnemius muscle of mice after sciatic nerve resection. Microsurgery 27, 487-493.

Storey, K. B. and Storey, J. M. (2007). Tribute to P. L. Lutz: putting life on 'pause' molecular regulation of hypometabolism. J. Exp. Biol. 210, 1700-1714.

Trendelenburg, A. U., Meyer, A., Rohner, D., Boyle, J., Hatakeyama, S. and Glass, D. J. (2009). Myostatin reduces Akt/TORC1/p70S6K signaling, inhibiting myoblast differentiation and myotube size. Am. J. Physiol. Cell Physiol. 296, C1258-C1270.

Tsuchida, K. (2004). Activins, myostatin and related TGF-beta family members as novel therapeutic targets for endocrine, metabolic and immune disorders. Curr. Drug Targets 4, 157-166.

Whittemore, L. A., Song, K., Li, X., Aghajanian, J., Davies, M., Girgenrath, S., Hill, J. J., Jalenak, M., Kelley, P., Knight, A. et al. (2003). Inhibition of myostatin in adult mice increases skeletal muscle mass and strength. Biochem. Biophys. Res. Commun. 300, 965-971.

Wickler, S. J., Hoyt, D. F. and van Breukelen, F. (1991). Disuse atrophy in the hibernating golden-mantled ground squirrel, Spermophilus lateralis. Am. J. Physiol. 261, R1214-R1217.

Zhu, X., Topouzis, S., Liang, L. F. and Stotish, R. L. (2004). Myostatin signaling through Smad2, Smad3 and Smad4 is regulated by the inhibitory Smad7 by a negative feedback mechanism. Cytokine 26, 262-272. 